\title{
РЕОЛОГІЧНІ ДОСЛІДЖЕННЯ ГЕЛЮ, ЩО МІСТИТЬ ВОДНИЙ ВИТЯГ 3 КСЕНОДЕРМИ, ДЛЯ МІСЦЕВОГО ЛІКУВАННЯ ОПІКІВ
}

\author{
Б. В. Вонс ${ }^{1}$, Ю. Я. Мельник ${ }^{2}$, Т. А. Грошовий${ }^{1}$ В. Й. Скорохода ${ }^{2}$, М. Б. Чубка $^{1}$
}

Тернопільський національний медичний університет імені І. Я. Горбачевського МОз України ${ }^{1}$

Національний університет «Львівська політехніка»², Львів

bohdana.vons@gmail.com

ІНФОРМАЦІЯ

Надійшла до редакції / Received: 29.05.2019

Після доопрацювання / Revised: 03.06.2019

Прийнято до друку / Accepted: 10.06.2019

\section{Ключові слова:}

карбомер;

ксенодерма;

гель;

динамічна в'язкість;

тиксотропні властивості; стабільність.
АНОТАЦІЯ

Мета роботи. Дослідження реологічних (тиксотропних) властивостей розробленого гелю та встановлення впливу температури на його стабільність. Матеріали і методи. Об'єктом дослідження обрано гель для місцевого лікування опіків на основі зшитого кополімеру акрилової кислоти карбомеру Carbopol ${ }^{\circledR}$ Ultrez 21, що містить водний витяг із ксенодерми та лідокаїну гідрохлорид. Реологічні властивості досліджували на ротаційному віскозиметрі «Rheomat-30». Досліджували такі характеристики гелю, як напруга зсуву, динамічна в'язкість і механічна стабільність.

Результати й обговорення. Для визначення типу течії, наявності тиксотропних властивостей і механічної стабільності гелю досліджено реограми його текучості. Під час експериментів встановлено, що досліджуваний гель $€$ неньютонівською рідиною та має пластичний тип текучості, що характеризує його як структуровану дисперсну систему. Наявність тиксотропних властивостей у досліджуваному гелі характеризує задовільну здатність до екструзії з туб і намазування.

Висновок. Визначено залежність реологічних властивостей, зокрема, структурної в'язкості досліджуваного гелю від температури. Розраховані значення механічної стабільності гелю дозволяють спрогнозувати стабільність препарату впродовж передбачуваного терміну його придатності.
Вступ. Опік - різновид травми тканин тіла, зумовлений дією тепла, випромінювання, електричного струму, хімічних речовин. Опікові травми впливають на життя мільйонів людей у всьому світі та $є$ одними із найпоширеніших видів травм, оскільки щорічно близько 6 мільйонів осіб звертаються за медичною допомогою в лікувальні заклади, проте більшість із них лікується амбулаторно [1, 2].

У 2016 році в Україні були одні 3 найвищих у світі показників смертності від опіків (4,55 на 100 тис.), а у 2017 році від опіків постраждало 7605 дітей і значна кількість дорослого населення. Тому лікування опіків
- це цілий комплекс спеціальних заходів, спрямованих на збереження життя постраждалих і відновлення цілісності шкірних покривів.

Популярним впродовж останніх десятиліть $€$ використання м'яких лікарських фрорм (МЛФ) на водорозчинних основах для лікування опіків у всіх фразах ранового процесу, адже опікові рани актуальна проблема сучасної медицини. Тому перспективним і доцільним є створення нових лікарських засобів (ЛЗ) у вигляді МЛФ і розширення асортименту лікарських фрорм, які б стимулювали регенераторні процеси шкіри та покращували б загоєння ран [3].

ISSN 2312-0967. Фармацевтичний часопис. 2019. № 2 
За останні роки популярністю серед МЛФ користуються гелі, які $€$ найоптимальнішою лікарською фрормою для місцевого лікування поверхневих опіків і для покращення загоєння ран після трансплантацій. Гелі $€$ безпечними для шкіри та зручними у застосуванні, рівномірно розподіляються на опіковій поверхні, утворюючи захисну плівку, проявляють охолоджувальну дію під час нанесення на шкіру внаслідок випаровування води, забезпечують рівномірне вивільнення активного фрармацевтичного інгредієнта, а також є економічно доступними [4].

У фрармації як гелеутворювачі широко використовуються синтетичні високомолекулярні зшиті полімери акрилової кислоти, зокрема карбомери [5]. Компанія «Lubrizol Advanced Materials» випустила на ринок карбомери під назвою Carbopol $^{\circledR}$ Ultrez, які швидко диспергуються і легко набрякають у воді, що значно полегшує технологічний процес. Карбомери є модифрікаторами реологічних властивостей і стабілізаторами гетерогенних дисперсних систем і можуть забезпечити біофармацевтичні властивості гелів і контрольоване вивільнення лікарських речовин із них [5].

Зшитий алкілакриловий кополімер Carbopol ${ }^{\circledR}$ Ultrez 21 ми обрали як основу для водорозчинного лікувального гелю, оскільки він за низьких концентрацій утворює гелі з високою структурною в'язкістю і контрольованими в'язкісними властивостями, які характеризуються гіпоалергенністю, високою абсорбцією і сумісністю з багатьма активними і лікарськими речовинами, термічною, мікробіологічною стабільністю та хімічною стійкістю при зберіганні [6].

Вивчаючи структурно-механічні властивості МЛФ, можна об'єктивно та ретельного проаналізувати поведінку препарату протягом передбачуваного терміну використання.

Важливими показниками гелів є консистенція, яку можна коригувати враховуючи реологічні властивості системи, завдяки яким можна передбачити поведінку середовища в технологічних процесах, також вони $€$ важливими під час створення нових та вдосконаленні існуючих ЛЗ. За реограмами оцінюють тип текучості, а також наявність тиксотропних властивостей гелів.

Відомо, що тиксотропним є явище повільної зміни в'язкості або будь-яких реологічних властивостей, яке зумовлене десормацією матеріалу або його відновлення після зняття зовнішнього навантаження. Значення в'язкості в процесі збільшення і зменшення швидкості зсуву не збігаються між собою. Тиксотропні властивості залежать також від наявності електролітів, від значення рН та температури $[7,8]$.

Вивчення реологічних властивостей є важливими та необхідними у процесі створення рідких та м'яких лікарських форм.

Мета роботи - вивчення реологічних (тиксотропних) властивостей розробленого гелю та впливу зміни температури на його стабільність.
Фармацевтична технологія, біофармація, гомеопатія

Pharmaceutical technology, biopharmacy, homeopathy

Матеріали і методи. Об'єктом реологічних досліджень обрано гелі на основі карбомеру Carbopol ${ }^{\circledR}$ Ultrez 21 з водним витягом із ксенодерми та лідокаїном гідрохлоридом, призначеного для місцевого лікування опіків. Для приготування гелів використовували верхньопривідну мішалку «OS-60» (UOSlab $\left.{ }^{\circledR}\right)$.

Реограми, які відображають залежність дотичної напруги зсуву $\left(\tau_{r}\right)$ від градієнта швидкості зсуву $\left(D_{r}\right)$, знімали на ротаційному віскозиметрі «Rheomat-30» («Contraves AG») в інтервалі швидкостей зсуву від 0 до 452 c $^{-1}$ за температур 20, 35 і $50{ }^{\circ} \mathrm{C}$. За реограмами визначали тип текучості, динамічну в'язкість (п) розраховували за фрормулою [9]:

$$
\eta=\frac{\tau_{r}}{D_{r}}
$$

Під час досліджень зразки гелів термостатували 3 точністю $\pm 0,1{ }^{\circ} \mathrm{C}$ за допомогою термостата «UH-8» («MLW»), оснащеного протічною коміркою (термостатуюча рідина - вода демінералізована).

Методика ґрунтується на визначенні динамічної (структурної) в'язкості у діапазоні від 0,1 до 4·105 Па.с. Суть методу полягає у реєстрації моменту опору обертанню внутрішнього конуса вимірювального пристрою 3 досліджуваним матеріалом за різних градієнтах швидкості деформації з подальшим розрахунком структурної в'язкості за отриманими значеннями напруження зсуву.

Значення механічної стабільності гелю (МC) розраховували за фрормулою:

$$
\mathrm{MC}=\tau_{1} / \tau_{2}
$$

де $\tau_{1}$ - межі міцності структури до руйнування; $\tau_{2}$ - межі міцності після її руйнування.

Результати й обговорення. Важливими показниками МЛФ є їхня консистенція та здатність до намазування, яка пов'язана із напруженням зсуву, а також із стабільністю гелю при зміні температурних режимів зберігання. Оптимальна гелева основа повинна легко наноситись на пошкоджену поверхню шкіри, мати достатню текучість, сприяти вивільненню діючої речовини з лікарської форми, сприяти зволоженню та пом'якшенню шкіри [8].

Для визначення стабільності структури гелю, типу течії та наявності тиксотропних властивостей були отримані повні реограми текучості досліджуваного гелю, які одержали методом неперервного руйнування структури як фрункції напруги зсуву.

Структурно-механічні властивості гелю впливають на швидкість дифузії лікарських речовин, від яких залежить терапевтичний ефект гелю. Динамічну в'язкість визначали за температур 20, 35 і $50{ }^{\circ} \mathrm{C}$ для визначення зміни реологічних показників, оскільки із підвищенням температури відбувається зниження структурно-механічних і споживчих характеристик гелів, що перешкоджає рівномірному вивільненню активного фрармацевтичного інгредієнта (рис. 1).

Зусилля, докладені пацієнтом під час нанесення гелю на шкіру, аналогічні напруженню, яке виникає в

ISSN 2312-0967. Pharmaceutical review. 2019. № 2 
Фармацевтична технологія, біофармація, гомеопатія Pharmaceutical technology, biopharmacy, homeopathy

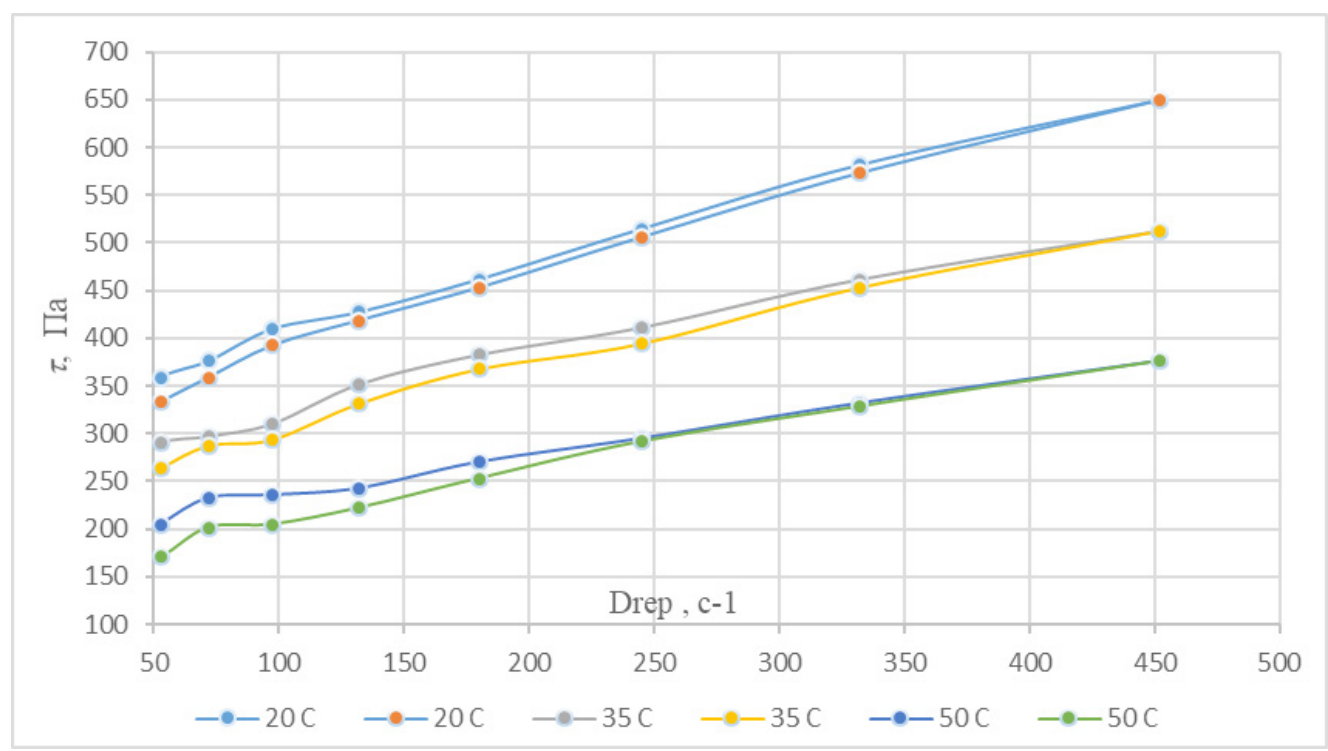

Рис. 1. Залежність дотичної напруги зсуву ( $)$ від градієнта швидкості зсуву $\left(D_{r}\right)$ гелю на основі Carbopol ${ }^{\circledR}$ Ultrez 21 за температур $20,35,50^{\circ} \mathrm{C}$.

ротаційному віскозиметрі під час зсуву в'язкопластичного матеріалу. Пропорційне відношення напруження до величини зсуву характеризує опір матеріалу зсувним десрормаціям за певної швидкості.

Аналізуючи отримані під час виконання експериментів реограми, можна зробити висновок про те, що досліджуваний гель $є$ неньютонівською рідиною та має пластичний тип текучості, що характеризує досліджуваний гель як структуровану дисперсну систему. 3 рисунка 1 видно, що реограми гелю характеризуються наявністю верхньої та нижньої кривої течії, які не збігаються між собою та утворюють «петлю гістерезису», площа якої свідчить про наявність тиксотропних властивостей, не зважаючи на зміну тем- пературних режимів [10, 11]. При цьому площа петель гістерезису практично однакова, але спостерігається закономірність зменшення напруження зсуву від швидкості зсуву із зростанням температури досліду. Наявність тиксотропних властивостей у досліджуваному гелі характеризує задовільну намазуваність на шкіру і здатність його до екструзії з туб. При підвищенні температурі до $50{ }^{\circ} \mathrm{C}$ спостерігається незначне зниження в'язкості гелю, що можна пояснити зміною механічної стабільності гелю.

Значення динамічної в'язкості дають змогу визначити ії залежність від градієнта швидкості зсуву. Залежність динамічної в'язкості гелю від швидкості зсуву, що відображені на рисунку 2, досліджували за температур

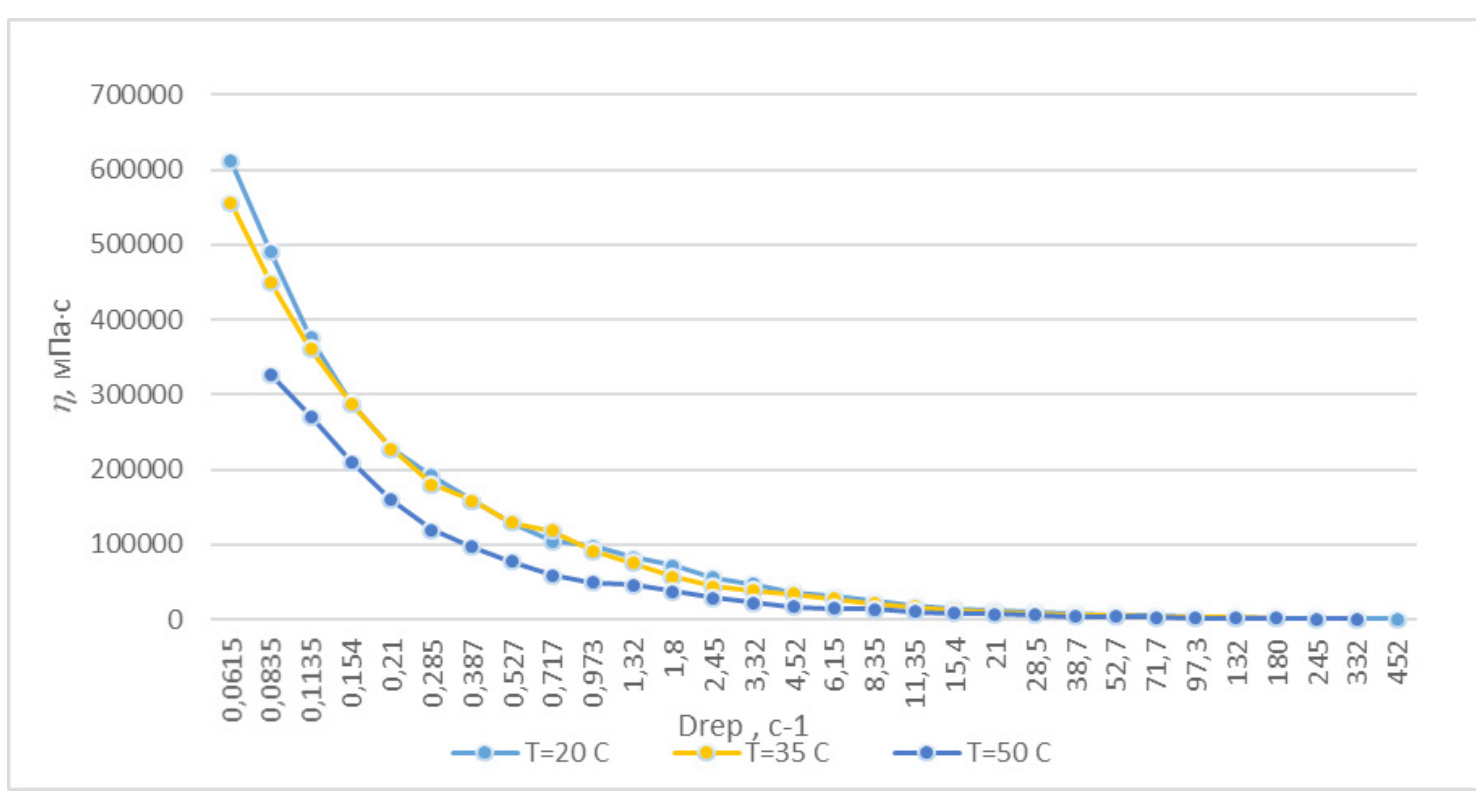

Рис. 2. Залежність динамічної в’язкості (п) досліджуваного гелю на основі Carbopol ${ }^{\circledR}$ Ultrez 21 від швидкості зсуву $\left(D_{\text {r }}\right)$ за температур 20,35 i $50^{\circ} \mathrm{C}$.

ISSN 2312-0967. Фармацевтичний часопис. 2019. № 2 
20, 35 і $50{ }^{\circ} \mathrm{C}$. Спостерігається зниження динамічної в'язкості під час зростання швидкості зсуву та температури, що є закономірними для структурованих дисперсних систем, що, у свою чергу, забезпечує необхідні параметри технологічного процесу виготовлення гелів [11].

Також ми розрахували показники механічної стабільності гелю, що характеризують ступінь руйнування полімерної структури. За температури $20^{\circ} \mathrm{C}$ цей показник складав 1,06 , при $35^{\circ} \mathrm{C}-1,11$, та при $50{ }^{\circ} \mathrm{C}$ - 1,12 відповідно [7, 8].

Висновки. Досліджено реологічні властивості гелю на основі карбомеру Carbopol ${ }^{\circledR}$ «Ultrez 21» 3 активними фрармацевтичними інгредієнтами (водним
Фармацевтична технологія, біофармація, гомеопатія Pharmaceutical technology, biopharmacy, homeopathy витягом з ксенодерми ті лідокаїну гідрохлоридом) для місцевого лікування опіків.

Доведено, що досліджуваний гель належить до неньютонівського типу пластичних рідин і проявляє тиксотропні властивості. Встановлено залежності реологічних властивостей, а саме динамічної в'язкості досліджуваного гелю від температури. Розраховані значення механічної стабільності гелів дають змогу прогнозувати стабільність препарату впродовж передбачуваного періоду зберігання.

Конфлікт інтересів: відсутній.

Conflicts of interest: authors have no conflict of interest to declare.

\title{
РЕОЛОГИЧЕСКИЕ ИССЛЕДОВАНИЯ ГЕЛЯ, СОДЕРЖАЩЕГО ВОДНОЕ ИЗВЛЕЧЕНИЕ ИЗ КСЕНОДЕРМЫ, ДЛЯ МЕСТНОГО ЛЕЧЕНИЯ ОЖОГОВ
}

\author{
Б. В. Вонс ${ }^{1}$, Ю. Я. Мельник ${ }^{2}$, Т. А. Грошовый ${ }^{1}$ В. И. Скорохода ${ }^{2}$, М. Б. Чубка ${ }^{1}$ \\ Тернопольский национальный медицинский университет имени И. Я. Горбачевского МОз Украины ${ }^{1}$ \\ Национальный университет «Львовская политехника», Львов ${ }^{2}$ \\ bohdana.vons@gmail.com
}

Цель работы. Исследование реологических (тиксотропных) свойств разработанного геля и установления влияния температуры на его стабильность.

Материалы и методы. Объектом исследования выбран гель для местного лечения ожогов на основе сшитого сополимера акриловой кислоты - карбомера Carbopol® Ultrez 2, содержащий водное извлечение из ксенодермы и лидокаина гидрохлорида. Реологические свойства исследовали на ротационном вискозиметре «Rheomat-30». Исследовали следующие характеристики геля как напряжение смещения, динамическая вязкость и механическую стабильность.

Результаты и обсуждение. Для определения типа течения, наличия тиксотропных свойств и механической стабильности геля исследовано реограммы его текучести. Во время экспериментов установлено, что исследуемый гель является неньютоновской жидкостью и имеет пластический тип текучести, что характеризует его как структурированную дисперсную систему. Наличие тиксотропных свойств в исследуемом гели характеризует удовлетворительную способность к экструзии из туб и намазывания.

Выводы. Определена зависимость реологических свойств, в частности, структурной вязкости исследуемого геля от температуры. Рассчитанные значения механической стабильности геля позволяют спрогнозировать стабильность препарата в течение предполагаемого срока его годности.

ключевые слова: карбомер; ксенодерма; гель; динамическая вязкость; тиксотропные свойства; стабильность.

\section{RHEOLOGICAL STUDIES OF GEL, CONTAINING A WATER EXTRACT WITH A XENODERM, FOR LOCAL TREATMENT OF BURNS}

\author{
B. V. Vons ${ }^{1}$, Y. Y. Melnyk ${ }^{2}$, T. A. Hroshovyi ${ }^{1}$, V. J. Skorokhoda ${ }^{2}$, M. B. Chubka ${ }^{1}$ \\ 1. Horbachevsky Ternopil National Medical University \\ ${ }^{2}$ Lviv Polytechnic National University \\ bohdana.vons@gmail.com
}

The aim of the work. Investigation of rheological (thixotropic) properties of the developed gel and determination of temperature influence on its stability.

Materials and Methods. The subject of the study was a gel for local treatment of burns based on a cross-linked copolymer of acrylic acid - a carbomer Carbopol $₫$ Ultrez 21 containing a water extract with xenoderm and lidocaine hydrochloride. The rheological properties studied on a rotary viscometer "Rheomat-30". The shear stress, dynamic viscosity and mechanical stability were studied as a characteristic of gel.

ISSN 2312-0967. Pharmaceutical review. 2019. № 2 
Фармацевтична технологія, біофармація, гомеопатія

Pharmaceutical technology, biopharmacy, homeopathy

Results and Discussion. In order to determine the flow type, the presence of thixotropic properties and the mechanical stability of the gel, the rheogram of its fluidity was investigated. During the experiments, it was found that the gel under investigation is a non-Newtonian fluid and had a plastic type of fluidity that characterizes it as a structured disperse system. The presence of thixotropic properties in the investigated gel characterizes the satisfactory ability to extrude from tubes and smearing.

Conclusions. Dependence of rheological properties, in particular, structural viscosity of the investigated gel on temperature is determined. Calculated values of the mechanical stability of the gel allow predicting the stability of the drug during its intended shelf life.

Key words: carbomer; xenoderm; gel; dynamic viscosity; thixotropic properties; stability.

\section{Список літератури}

1. Вонс Б. В. Проблема лікування опікових травм характеристика лікарських засобів для місцевого лікування опіків / Б. В. Вонс, М. Б. Чубка, Т. А. Грошовий // Актуальні питання фрармацевтичної і медичної науки та практики. - 2018. - Т. 11, № 1 (26) C. 119-125. DOI: 10.14739/2409-2932.2018.1.123731

2. Epidemiological study of pediatric burns at a tertiary care centre in South India / R. S. Powar, B. M. Sudhir, M. D. Prabhu [et al.] // Int J Community Med Public Health. - 2016. - Vol. 3. - P. 1242-1246. http://dx.doi. org/10.18203/2394-6040.ijcmph20161392

3. Vons B. V. Market analysis of semisolid dosage forms registered in Ukraine and research of excipients included to their formulas / B. V. Vons, M. B. Chubka, T. A. Groshovyi // Фармацевтичний часопис. - 2015. - № 1. - C. 55-61. https://doi.org/10.14739/24092932.2018.1.123731

4. Нормативно-директивні документи МО3 України [Електронний ресурс] / Міністерство охорони здоров'я України. - Режим доступу до інорормації : http://mozdocs.kiev.ua.

5. Исследование гелей с карбомерами методами ротационной вискозиметрии и спиновых зондов / А. Н. Ляпунов, Е. П Безуглая, Н. А. Ляпунов, И. А. Кирилюк // Химико-срармацевтический журнал. - 2015. - Т. 49, № 9. - С. 51-56. https://doi. org/10.30906/0023-1134-2015-49-9-51-56

\section{References}

1. Vons BV, Chubka MB, Hroshovyi TA [The problem of treatment of burns' wounds and characteristic of drugs for the local treatment of burns]. Aktualni pytannia farmatsevtychnoi i medychnoi nauky ta praktyky. 2018;11(1): 119-25. Available from: DOI: 10.14739/2409-2932.2018.1.123731. Ukrainian.

2. Powar RS, Sudhir BM, Prabhu MD, Rajput DU, Mallapur BN. Epidemiological study of pediatric burns at a tertiary care centre in South India. Int J Community Med Public Health. 2016;3: 1242-6. Available from: http:// dx.doi.org/10.18203/2394-6040.ijcmph20161392.

3. Vons BV, Chubka MB, Groshovyi TA. Market analysis of semisolid dosage forms registered in Ukraine and research of excipients included to their formulas. Farmatsevt chasop. 2015;1:55-61. Available from: https://doi. org/10.14739/2409-2932.2018.1.123731.
6. Carbopol ${ }^{\otimes}$ Ultrez 21Polymer, Technical Data Sheet (TDS-297), Lubrizol, Cleveland (2002). - URL : https:// www.ge-iic.com/files/fichas\%20productos/Carbopol_ Ultrez_21_hoja_tecnica.pdf.

7. Гладух $€$. В. Реологічні дослідження основи гелю 3 густим екстрактом лопуха / Є. В. Гладух, Сегі Анан Марсель, Н. О. Ніколайчук // Соціальна фрармація в охороні здоров'я. - 2017. - Т. 3, № 3. - С. 21-26. https://doi.org/10.24959/sphhcj.17.92

8. Carvalho F. C. Rheological, mechanical and bioadhesive behavior of hydrogels to optimize skin delivery system / F. C. Carvalho, G. Calixto // Drug. Dev. Ind. Pharm. - 2013. - Vol. 39. - Iss. 11. - P. 1750-1757. DOI: $10.3109 / 03639045.2012 .734510$

9. Державна Фармакопея України: в 3 т. / Державне підприємство "Український науковий фрармакопейний центр якості лікарських засобів". - 2-е вид. - Харків : Державне підприємство «Український науковий фармакопейний центр якості лікарських засобів», 2015. - T. 1. - 1128 c. ISBN 978-966-96478-8-7

10. Давтян Л. Л. Реологічні дослідження як основа технологічного процесу у разі створення нового лікарського засобу / Л. Л. Давтян, В. А. Ващук, Ю. П. Поліщук // Фармацевтичний журнал. - 2013. - № 4. - С. 52-58.

11. Шрамм Г. Основы практической реологии и реометрии / Г. Шрамм ; пер. с англ. - М. : Колос, 2003. - 312 c.

4. Regulatory documents of the Ministry of Health of Ukraine [Нормативно-директивні документи МO3 України]. Available from: http://mozdocs.kiev.ua. Ukrainian.

5. Lyapunov AN,. Bezuglaya EP, Lyapunov NA, Kirilyuk IA [Studying gels with carbomers by the rotational viscometry and spin probe techniques]. J Chem-Pharm. 2015;49(9):51-6. Russian. Available from: https://doi. org/10.30906/0023-1134-2015-49-9-51-56.

6. Carbopo ${ }^{\circledR}$ Ultrez 21Polymer, Technical Data Sheet (TDS-297), Lubrizol, Cleveland (2002). Available from: https://www.ge-iic.com/files/fichas\%20productos/Carbopol_Ultrez_21_hoja_tecnica.pdf.

7. Hladukh leV, Marcelle Seguy Anael, Nicolaychuk NO. [The rheological studies of the gel base with a dense extract from burdock]. Sotsialna farmatsiia v okhoroni

ISSN 2312-0967. Фармацевтичний часопис. 2019. № 2 
zdorovia. 2017;3(3): 21-6. Available from: https://doi. org/10.24959/sphhcj.17.92. Ukrainian.

8. Carvalho FC, Calixto G. Rheological, mechanical and bioadhesive behavior of hydrogels to optimize skin delivery system. Drug. Dev. Ind. Pharm. 2013;39(11): 17507. Available from: DOI: 10.3109/03639045.2012.734510.

9. State Pharmacopoeia of Ukraine in 3 vol., 2nd edition. [Державна Фармакопея України: в 3 т.] Kharkiv: State
Фармацевтична технологія, біофармація, гомеопатія Pharmaceutical technology, biopharmacy, homeopathy

Enterprise "Ukrainian Scientific Pharmacopoeial Center for Quality of Medicines"; 2015. Ukrainian.

10. Davtian LL, Vashchuk VA, Polishchuk YuP. Rheological research process as the basis for creating a new drug. Farmatsevt zhurnal. 2013;4: 52-8. Ukrainian.

11. Shramm G. Fundamentals of practical rheology and rheometry [Основы практической реологии и реометрии]. Moscow: Kolos; 2003. Russian.

\section{Відомості про авторів:}

Вонс Б. В. - аспірант, кафедра управління та економіки фрармації з технологією ліків, Тернопільський національний медичний університет імені І. Я. Горбачевського МОЗ України, Тернопіль, Україна. E-mail: bohdana.vons@gmail.com, ORCID 0000-0003-1276-0114

Мельник Ю. Я. - старший науковий співробітник кафедри хімічної технології переробки пластмас, Національний університет «Львівська політехніка», Львів, Україна. E-mail: yuriy.ya.melnyk@Ipnu.ua, ORCID 0000-0002-8516-9926

Грошовий Т. А. - д. фрармац. наук, проф., завідувач кафедри управління та економіки фрармації з технологією ліків, Тернопільський національний медичний університет імені І. Я. Горбачевського МОЗ України, Тернопіль, Україна. Еmail: grochovuy@ukr.net, ORCID 0000-0002-6427-2158

Скорохода В. Й. - д. тех. наук, проф., профр. кафедри хімічної технології переробки пластмас, директор Інституту хімії та хімічних технологій, Національний університет «Львівська політехніка», Львів, Україна. E-mail vskorohoda@ yahoo.com, ORCID 0000-0002-2352-5964

Чубка М. Б. - канд. фрармац. наук, доц. кафедри фрармації ННІ післядипломної освіти, Тернопільський національний медичний університет імені І. Я. Горбачевського МОЗ України, Тернопіль, Україна. E-mail: chubkacom@gmail.com, ORCID 0000-0002-5666-5496

\section{Information about authors:}

Vons B. V. - PhD student, Department of Pharmacy Management, Economics and Technology, I. Horbachevsky Ternopil National Medical University, Ternopil, Ukraine. E-mail: bohdana.vons@gmail.com, ORCID 0000-0003-1276-0114

Melnyk Y. Y. - Senior Research Fellow, Department of Chemical Technology of Plastics Processing, Lviv Polytechnic National University, Lviv, Ukraine. E-mail: yuriy.ya.melnyk@Ipnu.ua, ORCID 0000-0002-8516-9926

Hroshovyi T. A. - DS (Pharmacy), Professor, Head of the Department of Pharmacy Management, Economics and Technology, I. Horbachevsky Ternopil National Medical University, Ternopil, Ukraine. E-mail: grochovuy@ukr.net, ORCID 0000-0002-6427-2158

Skorokhoda V. J. - DS (Technique), Professor, Professor of the Department of Chemical Technology of Plastics Processing, Director of the Institute of Chemistry and Chemical Technology, Lviv Polytechnic National University, Lviv, Ukraine. E-mail vskorohoda@yahoo.com, ORCID 0000-0002-2352-5964

Chubka M. B. - PhD (Pharmacy), Associate Professor of the Pharmacy Department of Educational Scientific Institute of Postgraduate Education, I. Horbachevsky Ternopil National Medical University, Ternopil, Ukraine. E-mail: chubkacom@ gmail.com, ORCID 0000-0002-5666-5496

ISSN 2312-0967. Pharmaceutical review. 2019. № 2 